\title{
LA MUERTE DE DON QUIJOTE (SEGUNDA PARTE, CAPÍTULO LXXIV)
}

\author{
Leonardo Romero Tobar \\ Universidad de Zaragoza
}

\begin{abstract}
The last chapter of Second Part of Quixote closes the posibility of additional adventures, because don Quijote regains his reason and next occurs his death. The internal logic of the novel goes to this ending, that can be explained in accordance with anthropological and medical knowledge of the epoch. This end has had the power of provoke multiple responses. In this article the author insists on the function of "el sueño de la razón" and on the joy of the legacy of don Quijote in several modern works of art.
\end{abstract}

En los relatos, la anagnórisis y el cierre de la trama tienden a dar la re-composición ordenada de todo lo que ha estado suelto en el discurrir de personajes y acontecimientos. La vuelta a la razón de Alonso Quijano recupera, pues, un orden previo que las lecturas del hidalgo habían quebrantado. Abominar de la caballería y morir son dos momentos sucesivos en el término de la biografía de don Quijote que suponen la recuperación de la lucidez personal y la entrega sosegada del moribundo a las gentes que en su vida cotidiana han sido sus referentes de relación social. Marcel Proust evocaba la simultaneidad de estos acontecimientos en las páginas en que analizaba los sentimientos filiales de un parricida refiriéndose a "ce moment tardif de lucidité que les vies les plus ensorcelées de chimère peuvent bien avoir, puisque celle même de don Quichote eut la sien" (Proust 1973: 159).

La Segunda Parte de Don Quijote concluye con un rotundo epifonema, puesto que don Quijote "entre compasiones y lágrimas de los que allí se hallaron, dio su espíritu, quiero decir que se murió". La novela, en sus dos Partes, ha sido conducida hasta este momento, que en su apabullante sencillez, al mismo tiempo que cierra las posibilidades de otras aventuras abre los caminos de la libre imaginación de los lectores de la inmortal novela. Tributo el capítulo LXXII a la lógica interna de una historia verosímil y, simultáneamente, estímulo irrefrenable para las innúmeras lecturas hermenéuticas y creativas que ha generado en el curso de los siglos.

El triste acontecimiento, brutalmente humano, de la muerte de don Quijote, tal como cuenta este capítulo de la Segunda Parte, ha suscitado respuestas muy diversas entre sus lectores. Unas, instaladas en la meditación sobre análogas situaciones de otros textos literarios, como la que formulara Yvan Turguéniev en su memorable discurso de 1860, cuya conclusión abunda en los dispares fallecimientos de Hamlet y don Quijote ${ }^{1}$. Otras

\footnotetext{
1 "Hamlet y don Quijote mueren de una manera notable, ¡pero qué diferente es su fin! Las últimas palabras del primero son muy bellas; muere tranquilo; ordena a Horacio vivir, da su voto al joven Fortinbrás, el solo representante del derecho hereditario, no manchado por el crimen; pero no dirige sus miradas al porvenir. Todo lo demás es silencio, dice el escéptico al morir, y se callará para al eternidad. La muerte de don Quijote llena el alma de una indecible ternura; en ese momento el gran carácter del personaje es muerto a nuestros ojos. Cuando su antiguo escudero, creyendo consolarle, que aparecerán bien pronto para nuevas aventuras; No, responde el moribundo, dadme albricias, buenos señores, que ya yo no soy don Quijote de la Mancha, sino Alonso Quijano, a
} 
réplicas han ido encaminadas a la aplicación consolatoria de las propias expectativas del lector que las formula, así el discurso de don Juan Valera para la conmemoración académica del centenario de $1905^{2}$. Y muchas, en fin, han surgido como lanzadera de nuevas aventuras quijotescas imaginadas por nuevos narradores que, o bien dilatan el último latido del personaje cervantino -Gonçalves Crespo en "A morte de don Quixote" (1882), Camón Aznar en las prosas de El pastor Quijotiz (1969)-, o bien se entretienen en proseguir el tejido biográfico de los amigos y familiares que lo rodearon en sus momentos postreros, como ocurre en la reciente novela de Andrés Trapiello Al morir don Quijote (2004). Cabe, en fin, la negación radical del óbito del personaje, su traslado al ámbito ilimitado del mito en el que Don Quijote no puede ni debe morir, como titulaba en 2002 el poeta nicaragüense Jorge Eduardo Arellano una selección de Páginas cervantinas de Rubén Darío.

¡Cuántos textos literarios han sido escritos para su conclusión en la muerte de un personaje! En este aspecto el Quijote no difiere de las fórmulas empleadas en relatos de todos los tiempos y todas las literaturas. Lo que resulta singular de nuestro texto es que, desde su eminente jerarquía, ha suscitado las más variadas interpretaciones porque, al fin y al cabo, la muerte, además de clausurar el discurso de una vida, ilumina por sí misma el sentido de la misma. Y la muerte de don Quijote ha podido ser leída tanto como renuncia al ideal por el que combatía el caballero manchego como coronación del buen sentido y el equilibro razonable, tanto como el efecto del "oscuro proceso de un sueño" -lo sostenía Borges- como la confesión de que la vida no fue sino un "sueño de locura" -así lo mantenía Unamuno puesto a rematar su Vida de don Quijote y Sancho-. Dos lecturas las de Borges y Unamuno que, desde la autoridad de sus autores, amenguan lo que se pueda decir después de ellas.

\section{EL EPISODIO FINAL Y LA VEROSIMILITUD DEL RELATO ${ }^{3}$}

La mejor tradición filológica ha desentrañado las referencias a que remiten las alusiones de este capítulo sobre las creencias antropológicas y las prácticas mortuorias que estaban vigentes en el tiempo en que se escribió. Por de pronto, y para mayor paradoja con lo que ocurría en las novelas de caballería, don Quijote fallece en su lecho doméstico, rodeado de seres reales y de una muerte que médicamente podía explicarse como muerte natural: "Hallóse el escribano presente y dijo que nunca había leído en ningún libro de caballería que algún caballero andante hubiese muerto en su lecho tan sosegadamente y tan cristiano como don Quijote". Es una situación que en la literatura caballeresca sólo tenía paralelo -se ha dicho ya muchas veces- con la muerte de Tirant lo Blanc, una novela en la

\footnotetext{
quien mis costumbres dieron el renombre de bueno. ¡Alonso el Bueno! Esta palabra admirable creada aquí por primera y última vez conmueve singularmente al lector" (Turgueniev 1879: 470-471).

2 "Alonso Quijano no la tema (a la muerte), ni la desea, porque ama la vida, porque el ansia de goces y de venturas, superiores acaso a nuestra condición y a nuestros merecimientos, no le acibara o emponzoña lo presente con el anhelo atormentador de un porvenir soñado. Ni a la prolongación de los tiempos, durante la vida terrestre del linaje humano, ni fuera de esta vida, a más altas y ultramundanas esferas, acude Cervantes para consuelo de nuestras cuitas, para consuelo de nuestros infortunios y para justificación de la Providencia divina" (Valera 1905: 34).

${ }^{3}$ Para documentar la información sintetizada en este apartado, véanse las anotaciones de Martín de Riquer y Francisco Rico en sus respectivas ediciones que resumen lo fundamental que se ha dicho sobre el realismo histórico que revisten las alusiones contenidas en este episodio.
} 
que, como aseveraba el cura en el escrutinio de la librería (Quijote, I, cap. VI), “comen los caballeros, y duermen y mueren en sus camas, y hacen testamento antes de su muerte, con estas cosas de que todos los demás libros deste género carecen".

En este capítulo LXXIV don Quijote es atendido por el médico, se confiesa, hace testamento y manifiesta su despedida de los seres que le tienen afecto y lo rodean. La concreta realidad histórica a la que remiten estas situaciones es tan efectiva que, incluso el arranque literal del capítulo -“como las cosas humanas no sean eternas..."-, reproduce fórmulas habituales en la redacción notarial de los testamentos en la época. Lo mismo puede decirse del sigilo sacramental que aplica el cura a la confesión del moribundo y del lamento con que éste excusa no haber leído libros que hubieran sido para él "luz del alma"4. La posible enfermedad - "fue el parecer del médico que melancolía y desabrimientos le acababan"- que causa su fallecimiento también se explica desde las convenciones culturales de la época, puesto que para la tradición trovadoresca, el amor "en su forma más aguda desembocaba en la melancolía" y ésta era "el "humor más enemigo de la vida" (Avalle-Arce 1976: 239) según marcaban los saberes médicos establecidos (Otis Green 1966: 1967). Las "mandas", en fin, que don Quijote lega a los suyos introducen el irónico matiz, también realista, de la satisfacción que las buenas herencias llevan consigo ya que "esto del heredar algo borra o templa en el heredero la memoria de la pena que es razón que deje el muerto".

Thomas Mann (1935), lector del Quijote en su travesía marítima desde Europa hacia Nueva York, se enfrenta la víspera de su desembarco con el relato de la muerte de don Quijote. En reacción de novelista experimentado supone varios desenlaces para el final de la novela y encuentra que la solución aportada por Cervantes era necesaria para "salvar el alma de la razón en Don Quijote antes de su muerte" y lamenta, acto seguido, el que "para que este acto respondiera al corazón cumplidamente, debiera el poeta habernos hecho amar menos su sinrazón". Pero la compasión del lector entregado al proyecto vital del personaje cervantino se atenúa si, de acuerdo con la lectura de Jorge Guillén (1952), se atiende y se entiende que lo narrado en el capítulo LXXIV es la "muerte de Alonso Quijano", "el ser que no llega a ser quien es" y que ha de "dejarse morir desde lo más íntimo de su alma indomable".

La lógica del discurso narrativo conduce necesariamente a esta conclusión de la novela. Recuérdese cómo en los textos post-liminares de la Primera Parte se recogían varios epitafios de los académicos de Argamasilla en honor y memoria de los difuntos don Quijote y Dulcinea y en loor de Sancho y Rocinante. Aquella broma de 1605 sobre una defunción fantaseada no arredró al autor del falso Quijote, del que la Segunda Parte de Cervantes no ahorra consideraciones abundantes y sabrosas y que en este capítulo LXXIV suscitan un epitafio del bachiller Sansón Carrasco, el testimonio del escribano "para quitar la ocasión de que algún otro autor que Cide Hamete Benengeli le resucitase falsamente" y el elocuente discurso que éste último endereza a su propia pluma que, en figura de sinécdoque del escritor, confiesa su íntima relación genesiaca con el hidalgo manchego "a despecho y pesar del escritor fingido y tordesillesco" y clama para que éste "deje reposar en la

\footnotetext{
${ }^{4}$ Los comentaristas han anotado que la expresión es alusión trasparente al catecismo titulado Luz del alma cristiana de fray Felipe de Meneses que fue editado en varias ocasiones durante el siglo XVI.
} 
sepultura los cansados y ya podridos huesos de don Quijote (...) imposibilitado de hacer tercera jornada y salida nueva".

La asociación teatral que introduce la palabra "jornada" se extiende al intenso teñido de matices escénicos que penetra toda la novela (Baras Escolá 1989) y confiere una resonancia singular a la negativa con la que Alonso Quijano responde a las invitaciones de Sancho y Sansón Carrasco para que emprenda una aventura pastoril, cuando aquel afirma frente a estos que "ya en los nidos de antaño, no hay pájaros hogaño". Este refrán es el mismo que enunciaba Miguel de Cervantes en el prólogo de sus Ocho comedias y ocho entremeses (1615) para referirse a otros aconteceres de su propia biografía de autor de teatro: "volví a componer algunas comedias; pero no hallé pájaros en los nidos de antaño". Quede esta correspondencia textual para la discusión de lo que tantas veces se ha planteado a propósito de la superposición de voces narradoras en el Quijote (Montero Reguera 1997: 156-165) y de las intervenciones del propio Cervantes en el curso del relato y a propósito también del eslabón original que le ha generado, un origen que oscila entre el "yo, aunque parezco padre, soy padrastro de don Quijote" afirmado por el propio novelista en el "Prólogo" de la Primera Parte y el "para mí sola nació don Quijote, y yo para él" que afirma la pluma de Benengeli en el capítulo aquí comentado.

La muerte del personaje cierra, pues, la novela y la remota posibilidad de una nueva serie de aventuras quijotescas, este es el resultado de la articulación interna del episodio final en la estructura de la obra. Ahora bien, la muerte de cada ser vivo se implica en el recorrido de su trayectoria vital e invita a pensar en su función reveladora sobre el sentido de cada vivir. Lo recordaba, en términos de filosofía existencial, Santiago Montero Díaz (1957: 121-122) en párrafos conmovedores: "La razón recuperada otorga al moribundo la posibilidad de percibir toda su vida unitariamente, como un proceso cohesivo y unívoco (...). Porque en definitiva la muerte no es una mera cesación, es el acto más personal de la existencia, en que culmina la significación misma de la vida".

\section{EL SUEÑO DE LA MUERTE}

Lo que sigue podría ampliarse a las diversas situaciones de personajes difuntos o que mueren las obras cervantinas, incluida la Primera Parte del Quijote, donde el lector asiste al entierro del suicida Grisóstomo (XII-XIV), percibe con Sancho el perfil de la "Triste Figura" de don Quijote cuando se encuentra con la comitiva que traslada el cadáver del caballero de Baeza muerto de calenturas (capítulo XIX), escucha con los otros oyentes de la venta el desdichado final del "curioso impertinente" (XXXV) y, en la Segunda Parte, asiste al "gustoso suceso" del suicidio simulado de Basilio el pobre (XXIX-XXXI). Pero de todos los casos, el del tránsito de Alonso Quijano es singularmente peculiar, tanto por la naturalidad con que se produce como por la trascendencia significativa que los lectores le han dado.

Don Quijote ha "muerto naturalmente" en su cama, después de recobrar la razón y abominar de su locura precedente, ya lo sabemos, pero olvidamos a veces que todo ello ocurre después de sufrir "una calentura que le tuvo seis días en la cama", que el síntoma médico más llamativo que muestra es el sueño que le acomete en el que "durmió de un tirón, como dicen, más de seis horas" y que su despertar supone el regreso a la circunstancia cotidiana de los tres amigos, el escudero y las dos mujeres de su casa. El texto no da noticia de lo que pudo soñar don Quijote, contra lo que había ocurrido en el episodio 
de la cueva de Montesinos (Segunda Parte, XXII-XXIV), de donde aquél retornaba a la superficie dormido y con el cuento de un fantástico relato que, aparte de remitir al proceso de la gestación de la propia novela (Egido 1994: 137-178), obliga a que Benengeli apostille sobre la veracidad de esta aventura apelando al buen sentido del lector ya que "se tiene por cierto que al tiempo de su fin y muerte dicen que se retra(c)tó della y dijo que él la había inventado".

“¡Pobre Don Quijote! A lindero de morir, y a la luz de la muerte, confiesa y declara que no fue su vida sino sueño de locura. ¡La vida es sueño!” La compasión de Unamuno renueva la vieja metáfora que relaciona el sueño y la muerte, metáfora vivida ahora desde la personal tensión existencial del escritor vascongado, puesto que el sueño al que alude es el de los que están tocados de la misma locura del no morir, del hambre de inmortalidad que acució siempre a aquel gran "excitator Hispaniae". Pero el último sueño de don Quijote es un sueño fisiológico sobre el que el texto cervantino ahorra precisar las figuraciones experimentadas por el durmiente, aunque sea prolijo en declarar sus efectos en el ánimo del hidalgo Alonso Quijano, quien recupera ahora el renombre de "bueno", el mismo apelativo que se había aplicado a Sancho en memorable ocasión.

No carecen de sentido las correlaciones alusivas y onomásticas que puntean la novela desde el principio hasta el fin y que, en el caso del adjetivo "bueno", señala los efectos positivos que tantas veces ha provocado el texto de Cervantes. Dar a don Quijote y a Sancho la misma calificación es un rasgo más de la integración identificadora de los dos personajes y de la apertura significativa que ambos propician. "Caballero andante nací y caballero andante he de morir" afirma el caballero en una ocasión solemne y Sancho confiesa a la duquesa su fidelidad al proyecto aventurero de su amo: "así es imposible que nos pueda apartar otro suceso que el de la pala y el azadón” (II, cap. XXXIII).

Al hilo de estos asertos, Ángel del Río volvía a la reflexión sobre el orteguiano "equívoco de don Quijote", para incidir en la respuesta existencialista que supone la asunción de la propia muerte en el curso de cada existencia. Al morir don Quijote, "cae el telón, pero la vida, la representación, el equívoco no se acaba y cada cual seguirá viviendo entre verdades y mentiras según su naturaleza" (del Río 1959: 219).

La venerable relación analógica entre el sueño y la muerte cobra en este capítulo final el valor polisémico que revisten todos los elementos constitutivos de la novela y vale tanto considerar el sueño como renuncia igual que verlo como recuperación. Dos polos opuestos por el vértice: el "prosaísmo deliberado" del que hablaba Spitzer si se ilumina la despedida de los ideales caballerescos y el emblema ilustrado que iluminó Goya: "El sueño de la razón produce monstruos". He mantenido en otro lugar (Romero Tobar 1993) que el célebre "Capricho 43" no es sino un avance gráfico y semántico de la aguada sepia que el pintor aragonés había dedicado al hidalgo manchego hacia 1817.

Pero, en último término del relato, queda el efecto de ternura humana que viven los destinatarios de las mandas, patente en la expresión del "llorar tiernamente" y el regocijarse de Sancho Panza. La duplicidad de sentimientos de los herederos del hidalgo es trágica y cómica al mismo tiempo, igual que ha sido ambivalente la biografía del personaje que acaba de morir. Ahora bien, una mezcla de efectos similares han exhibido otras creaciones literarias construidas a la zaga de los héroes cervantinos. El don Quijote recogido en un convento de los Capítulos que se le olvidaron a Cervantes (1895) de 
Montalvo, el de la teatralización de Bulgákov (1938) que aconseja a su sobrina que se case con hombre que "no esté apasionado por los libros de caballerías, pero que tenga alma de caballero" o la Fortunata de Galdós cuyo fallecimiento es una escena reduplicativa de la muerte de don Quijote (Romero Tobar 1987).

Fortunata, moribunda, reúne en torno a su lecho a casi todas las personas con las que ha estado relacionada su existencia. A falta de escribano al que dictar el testamento, Estupiñá pergeña en un papel la última voluntad de la mujer; un clérigo, el padre Nones, procura atenderla en confesión y los acompañantes se alborotan -Estupiñá, repitiendo a Sancho, exclama: "Fortunata, Fortunatita, abra usted los ojos y no se nos muera así tan tontamente..."- y se regocijan, pues hay también herencia, y de hondo calado, para la familia Santa Cruz, ya que Fortunata en las mandas de su testamento entrega a Jacinta Arnáiz el mayor bien del que podía disponer: su hijo, el fruto de su vientre.

Muertes como las de estas recreaciones modernas de la vivida por el inmortal personaje cervantino dan al acto final de la existencia humana la dimensión simbólica y trascendente que imaginaba Bécquer al contemplar en un enterramiento toledano la estatua yacente de una mujer: "iqué sueño el del sepulcro tan tranquilo!"

\section{REFERENCIAS BIBLIOGRÁFICAS}

AVALlE-ARCE, Juan Bautista, Don Quijote como forma de vida, Madrid, Castalia, 1976.

BARAS ESCOLÁ, Alfredo, "Teatralidad del Quijote", Anthropos, XCVIII-XCIX (1989), pp. 98-101.

BORGES, Jorge Luis, "Análisis del último capítulo del Quijote", Revista de la Universidad de Buenos Aires, I (1956), pp. 28-36.

EGIDO, Aurora, Cervantes y las puertas del sueño. Estudios sobre "La Galatea", "El Quijote" y "El Persiles", Barcelona, P.P.U., 1994.

GREEN, Otis H., "Melancholy and Death in Cervantes", Hispanic Studies in Honor of Nicholson B. Adams, Chapel Hill, 1966, pp. 49-55.

GREEN, Otis H., "Two Deaths: Don Quijote and Marianela", Anales Galdosianos, II (1967), pp. 131-133.

GUILLÉN, Jorge, "Vida y muerte de Alonso Quijano", Romanische Forschungen, 64 (1952), pp. 102-113.

MANN, Thomas, "Meerfahrt mit Don Quixote", trad. española, Revista de Occidente, 48 (1935), pp. 69-105 y 163-189.

MONTERO DÍAZ, Santiago, Cervantes, compañero eterno, Madrid, Editorial Aramo, 1957, pp. 79-125.

MONTERO REGUERA, José, El “Quijote” y la crítica contemporánea, Alcalá, Centro de Estudios Cervantinos, 1997.

PROUST, Marcel, "Sentiments filiaux d'un parricide", Le Figaro, 1-II-1907; reed. Contre Sainte-Beuve, précedé de Pastiches et mélanges et suivi de Essais et articles, Tours, Gallimard, 1973, pp. 150- 159.

RÍO, Ángel del, "E1 Equívoco del Quijote", Hispanic Review, XXVII (1959), pp. 200-221.

ROMERO TOBAR, Leonardo, "Las muertes de Fortunata”, ABC, 17-II-1987. 
ROMERO TOBAR, Leonardo, "Capricho 43: el emblema de un mito", Mitos. Actas del VII Congreso Internacional de la Sociedad Española de Semiótica, Zaragoza, Anexos de Tropelías, I, 1999, pp. 73-81.

SPITZER, Leo, "Thomas Mann, la muerte de Don Quijote", Revista de Filología Hispánica, 2 (1940), pp. 46-48.

TURGUENIEV, Iván, “Gamlet i Don-Kikhot"; trad. española, "Hamlet y Don Quijote", Revista Contemporánea, XXIII (1879), pp. 453-471.

UNAMUNO, Miguel de, Vida de Don Quijote y Sancho; reed. En Obras Completas. Ensayo II, Madrid, Afrodisio Aguado, 1958 [1905], IV, 363-382.

VALERA, Juan, Discurso que por encargo de la Real Academia Española escribió el Excmo. Sr. D.----para conmemorar el tercer centenario de la publicación del Ingenioso Hidalgo D. Quijote de la Mancha leido por el Excmo. Sr. D. Alejandro Pidal y Mon; Madrid, Tip. de la "Revista de Archivos, Bibliotecas y Museos”, 1905. Reed. en Obras Completas, Madrid, Aguilar, III, 1245-1258. 


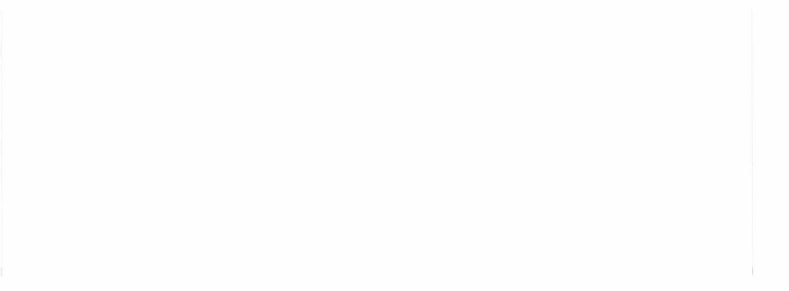

